\title{
Ecotoxic effects of loratadine and its metabolic and light-induced derivatives
}

\author{
lesce, Maria Rosaria
}

2019-04-15

lesce , M R , Lavorgna, M , Russo , C , Piscitelli , C , Passananti , M , Temussi , F , DellaGreca , M , Cermola , F \& Isidori , M 2019 , ' Ecotoxic effects of loratadine and its metabolic and light-induced derivatives ' , Ecotoxicology and Environmental Safety , vol. 170 , pp. 664-672 . https://doi.org/10.1016/j.ecoenv.2018.11.116

http://hdl.handle.net/10138/329052

https://doi.org/10.1016/j.ecoenv.2018.11.116

cc_by_nc_nd

acceptedVersion

Downloaded from Helda, University of Helsinki institutional repository.

This is an electronic reprint of the original article.

This reprint may differ from the original in pagination and typographic detail.

Please cite the original version. 
Ecotoxic effects of loratadine and its metabolic and light-induced derivatives

E-mail address: marina.isidori@unicampania.it

\section{*Corresponding authors}

Maria Rosaria Iesce

E-mail address: iesce@unina.it

Phone: +39081674334

Marina Isidori

Phone: +390823274565

Maria Rosaria Iesce ${ }^{1 *}$, Margherita Lavorgna ${ }^{2}$, Chiara Russo ${ }^{2}$, Concetta Piscitelli ${ }^{2}$, Monica Passananti $^{3}$, Fabio Temussi ${ }^{1}$, Marina DellaGreca ${ }^{1}$, Flavio Cermola ${ }^{1}$, Marina Isidori ${ }^{2 *}$

${ }^{1}$ Dipartimento di Scienze Chimiche, Università Federico II, Via Cintia, 4, I-80126 Napoli, Italy

${ }^{2}$ Dipartimento di Scienze e Tecnologie Ambientali, Biologiche e Farmaceutiche, Università della Campania "Luigi Vanvitelli", Via Vivaldi 43, I-81100 Caserta, Italy ${ }^{3}$ Institute for Atmospheric and Earth System Research/Physics, Faculty of Science, Gustaf Hällströmin katu 2a, FI-00014, University of Helsinki, Finland 
Abstract

38 Loratadine and desloratadine are second-generation antihistaminic drugs. Because of human

39 administration, they are continuously released via excreta into wastewater treatment plants and occur in surface waters as residues and transformation products (TPs).

41 Loratadine and desloratadine residues have been found at very low concentrations (ng/L) in the aquatic environment but their toxic effects are still not well known. Both drugs are light-sensitive even under environmentally simulated conditions and some of the photoproducts have been isolated and characterized. The aim of the present study was to investigate the acute and chronic ecotoxicity of loratadine, desloratadine and their light-induced transformation products in organisms of the aquatic trophic chain. Bioassays were performed in the alga Pseudokirchneriella subcapitata, the rotifer Brachionus calyciflorus and in two crustaceans, Thamnocephalus platyurus and Ceriodaphnia dubia. Loratadine exerted its acute and chronic toxicity especially on Ceriodaphnia dubia (LC50: $600 \mu \mathrm{g} / \mathrm{L}$, EC50: $28.14 \mu \mathrm{g} / \mathrm{L}$ ) while desloratadine showed similar acute toxicity among the organisms tested and it was more chronically effective compound in Ceriodaphnia dubia and Pseudokirchneriella subcapitata. Generally, transformation products were less active both in acute and chronic assays.

Keywords: antihistaminic drug; loratadine; desloratadine; acute toxicity; chronic toxicity; photoproducts.

\section{Highlights}

61 - Loratadine was irradiated by UVB and sunlight and its photoproducts were isolated and characterized.

63 - Loratadine, desloratadine and light-induced TPs were tested in aquatic organisms.

64 -Generally, transformation products were less active both in acute and chronic assays. 
72 Drugs are continuously released as mixtures of parent compounds and metabolites and enter the aquatic environment through hospital and municipal wastewaters. Here, these mixtures may undergo transformations due to redox or light-induced reactions, hydrolysis, and other reactions leading to transformation products, in some cases more harmful than parent compounds (DellaGreca et al., 2014; Passananti et al., 2015; Isidori et al., 2016). The importance of these events in the breakdown of drugs has stimulated a large number of researches concerning kinetics, degradation mechanism, isolation and toxicity of the transformation products (Lambropoulou and Nollet, 2014). Generally, the most commonly occurring drugs in the aquatic systems are the most administered. However, some classes of drugs highly utilized by patients are not detected in the waters because rapidly degraded, while in some cases drugs less utilized are detected at high concentrations because resistant to biodegradation. Among the most administered drugs, antihistamines are detected in surface waters because of their poor removal by conventional wastewater treatments (Kosonen and Kronberg, 2009; Radjenovic' et al., 2009; Valcarcel et al., 2011) and due to their low polarity and scarce volatility, they may represent a hazard for the aquatic ecosystem (Berninger and Brooks, 2010; Kristofco and Brooks, 2017).

Among antihistamines, ranitidine, difenidramine, cimetidine and loratadine are the most detected in the effluents of sewage treatment plants and the detection of loratadine in surface waters has exceeded therapeutic hazard values (THVs) showing the need of understanding the aquatic toxicology, hazards and risks associated with this drug (Kristofco and Brooks, 2017). Loratadine is a second-generation antihistaminic drug so called because it causes less sedation and drowsiness than the first-generation antihistamines used to treat allergic reactions, approved by US Food and Drug Administration in 1993. Loratadine is a selective inverse agonist of peripheral $\mathrm{H}_{1}$-receptors (Witiak, 1970, Peyrovi and Hadjmohammadi, 2015). It is mainly metabolized through the hepatic system to desloratadine, which is a pharmacologically active compound, deriving from the loss of carbamate moiety (Yumibe et al., 1996). Forty percent and $42 \%$ of the ingested loratadine dose is excreted unchanged in urine and the feces, respectively (Ramanathan et al., 2007). It has been detected in surface waters in Europe (in some Spanish river samples) in the low concentration range of 3.96-17.1 ng/L (Lopez-Serna et al., 2012) but also in wastewater effluents in Europe, NorthAmerica and Asia-Pacific with a maximum concentration of $58.5 \mathrm{ng} / \mathrm{L}$ (Kristofco and Brooks, 2017). Desloratadine has been detected in Europe with a maximum concentration of $81 \mathrm{ng} / \mathrm{L}$ (Kristofco and Brooks, 2017). Both drugs have also been recovered in lower amounts in marine water of Mediterranean coasts (Moreno-Gonzalez et al., 2015). Based on the antihistamines consumption data, loratadine and desloratadine should occur in wastewater at higher concentrations. 
However, loratadine has low affinity for suspended matter (octanol/water partition coefficient $\log$ P equal to 5 for loratadine and 3.2 for desloratadine; El-Awady et al., 2013) and therefore does not accumulate appreciably in sediments and remains in the water column (Moreno-

108 Gonzales et al., 2015). Loratadine is known as photolabile, in fact it is stated that the drug should 109 be stored protected from light (Parfitt, 1999). Its UV spectrum shows an absorption band at $\lambda 280$

$110 \mathrm{~nm}$ with a tail up to $300 \mathrm{~nm}$, hence the drug is able to adsorb sunlight at ground level and to 111 undergo light-induced transformations in the aquatic compartment. While its photostability has been 112 investigated, no data on photoproducts identification are reported (Abounassif et al., 2005). In this 113 context, we have examined the photochemical behavior of loratadine and desloratadine in aqueous 114 medium under UVB and sunlight irradiation in order to isolate and fully characterized the 115 photoproducts. For this purpose, concentrated solutions, far from environmental concentrations, 116 were used (DellaGreca et al., 2014). The ecotoxicological effects of the parent drug, its metabolite 117 and its transformation products were evaluated in producers and primary consumers.

\section{Materials and methods}

$120 \quad 2.1$ Chemicals

121 Loratadine (99.4\%, CAS Number: 79794-75-5) and desloratadine (99.6\%, CAS Number: 100643-

122 71-8) were purchased by Kemprotec. All chemicals were used without further purification unless 123 otherwise indicated. Solvents (acetonitrile, methanol and diethylether) were of HPLC grade and 124 were purchased from Sigma Aldrich. Water was of Milli-Q quality and was obtained from a Milli-Q 125 gradient system (Millipore).

\subsection{Apparatus}

127 2.2.1 Spectroscopic techniques

128 Nuclear magnetic resonance (NMR) spectra were recorded on a Varian Inova-500 instrument 129 operating at 499.6 and $125.6 \mathrm{MHz}$ for ${ }^{1} \mathrm{H}$ and ${ }^{13} \mathrm{C}$, respectively, and referenced with $\mathrm{CDCl}_{3}$. The 130 carbon multiplicity was evidenced by DEPT experiments. The proton couplings were evidenced by

$131{ }^{1} \mathrm{H}-{ }^{1} \mathrm{H}$ COSY experiments. The heteronuclear chemical shift correlations were determined by 132 HMQC and HMBC pulse sequences.

133 IR spectra were recorded on a Jasco FT/IR-430 instrument equipped with single reflection ATR 134 using $\mathrm{CHCl}_{3}$ as solvent.

135 UV-Vis spectra were recorded with a Varian Cary $300 \mathrm{UV}-\mathrm{Vis}$ spectrophotometer or on a 136 PerkinElmer Lambda 7 spectrophotometer.

$137 \quad$ 2.2.2 Chromatographic analysis 
138 HPLC experiments were carried out on an Agilent 1100 HPLC system, equipped with an UV

139 detector set at $254 \mathrm{~nm}$, using a RP-18 column (Gemini, $5 \mu \mathrm{m}, 110 \mathrm{~A}, 250 \mathrm{~mm} \times 4.6 \mathrm{~mm}$ ). at a flow 140 rate of $0.8 \mathrm{~mL} \mathrm{~min}^{-1}$.

141 The analysis of the solutions used for determining the kinetic constant of loratadine

142 photodegradation was carried out using the gradient elution as follows: at initial time $30 \%$

143 acetonitrile and $70 \%$ water for $7 \mathrm{~min}$, followed by an increase of acetonitrile up to $70 \%$ in two

144 minutes. Then, the same ratio was maintained constant for 24 minutes; finally, the initial ratio (30

$145 \%$ acetonitrile and $70 \%$ water) was reached in two minutes.

146 In other cases HPLC analysis was performed under isocratic conditions and $\mathrm{H}_{2} \mathrm{O} / \mathrm{CH}_{3} \mathrm{CN}$ 4:6 v/v 147 was used as eluent.

148 GC-MS analyses were performed on a 6890 MSD quadrupole mass spectrometer (Agilent

149 technologies) equipped with a gas chromatograph by using a Zebron ZB-5HT Inferno (5\%-Phenyl-

$15095 \%$-Dimethylpolysiloxane) fused silica capillary column (Column $30 \mathrm{~m}$ x $0.32 \mathrm{~mm}$ x $0.10 \mu \mathrm{m}$ )

151 from Phenomenex. The injection temperature was $250^{\circ} \mathrm{C}$, the oven temperature was held at $50^{\circ} \mathrm{C}$

152 for $3 \mathrm{~min}$ and then increased to $150^{\circ} \mathrm{C}$ at $12^{\circ} \mathrm{C} / \mathrm{min}$, increasing to $230^{\circ} \mathrm{C}$ at $18^{\circ} \mathrm{C} / \mathrm{min}$, to $280^{\circ} \mathrm{C}$ at

$15310^{\circ} \mathrm{C} / \mathrm{min}$ and finally to $300^{\circ} \mathrm{C}$ at $30^{\circ} \mathrm{C} / \mathrm{min}$ and held for $3 \mathrm{~min}$. Electron Ionization mass spectra

154 were recorded by continuous quadrupole scanning at $70 \mathrm{eV}$ ionization energy, in the mass range of

$155 \mathrm{~m} / \mathrm{z} 30-600$.

$156 \quad 2.2 .3$ Irradiation apparatus

157 The photoreactor (Multirays, Helios Italquartz) was equipped with six 15W lamps with a maximum 158 at $310 \mathrm{~nm}(\mathrm{UV}-\mathrm{B})$. Open quartz tubes $(1 \mathrm{~cm}$ optical path) and open and closed pyrex tubes $(20 \mathrm{~cm} \mathrm{x}$ $1591 \mathrm{~cm}, 25 \mathrm{~mL}$ ) were used.

$160 \quad 2.3$ Chromatographic separation materials

161 Analytical and preparative Thin Layer Chromatography (TLC) was made on Kieselgel $60 \mathrm{~F}_{254}$

162 plates with $0.2 \mathrm{~mm}, 0.5$ or $1 \mathrm{~mm}$ layer thickness, respectively (Merck).

1632.4 Experiments

164 2.4.1 Stability in aqueous solution in the dark

165 Loratadine (1) solutions $\left(1 \times 10^{-4} \mathrm{M}\right)$ in $\mathrm{H}_{2} \mathrm{O} / \mathrm{CH}_{3} \mathrm{CN}(9: 1, \mathrm{v} / \mathrm{v})$ at $\mathrm{pH} 4,7$ and 9 were prepared. The 166 acid and alkaline solutions were made using $\mathrm{NaOH} 2 \mathrm{M}$ and $\mathrm{HCl} 2 \mathrm{M}$ to adjust $\mathrm{pH}$ level. All

167 solutions were kept in the dark and analyzed by HPLC (isocratic conditions) at $12 \mathrm{~h}$ and $48 \mathrm{~h}$.

$168 \quad 2.4 .2$ Kinetic constant and quantum yield determination

169 Kinetics data were obtained by irradiating the drug $\left(1 \times 10^{-4} \mathrm{M}\right.$ solution in $\mathrm{H}_{2} \mathrm{O} / \mathrm{CH}_{3} \mathrm{CN} 9: 1$, v/v) in 170 open quartz tubes and monitoring the solution at fixed time intervals by HPLC using the proposed 171 gradient elution. The time evolution was fitted with a pseudo-first order equation $\mathrm{C}_{0}=\mathrm{C}_{\mathrm{t}} \mathrm{x} \mathrm{e}^{-\mathrm{Kt}}$ 
172

173

174

175

176

177

178

179

180

181

182

183

184

185

186

187

188

189

190

191

192

193

194

195

196

197

198

199

200

201

202

203

204

where $\mathrm{C}_{0}$ is the initial drug concentration, $\mathrm{C}_{\mathrm{t}}$ the concentration at time $\mathrm{t}$ and $\mathrm{k}$ the pseudo-first order degradation rate constant.

The incident photon flux $\left(4.98 \times 10^{21}\right.$ photons $\left.\mathrm{m}^{-2} \mathrm{~s}^{-1}\right)$ in solution, used to calculate the quantum yield of loratadine, was calculated using p-nitroanisole/pyridine actinometer (Dulin and Mill, 1982).

2.4.3 Irradiation experiments. Two solutions of loratadine in $\mathrm{H}_{2} \mathrm{O} / \mathrm{CH}_{3} \mathrm{CN}\left(9: 1\right.$, v/v, 1 x $\left.10^{-4} \mathrm{M}\right)$ and $\mathrm{H}_{2} \mathrm{O} / \mathrm{CH}_{3} \mathrm{CN}\left(75: 25\right.$, v/v, $\left.1 \times 10^{-4} \mathrm{M}\right)$ were irradiated in open quartz tube and analysed by HPLC at selected times. The photoproducts were identified by HPLC comparing their $\mathrm{R}_{\mathrm{t}}$ values with those of standard compounds which were isolated and characterized by performing preparative

photochemical experiments (see below). An aliquot of the $\mathrm{H}_{2} \mathrm{O} / \mathrm{CH}_{3} \mathrm{CN}(75: 25$, v/v, 1 x 10-4 M) was analyzed by GC-MS after 6 min irradiation.

\subsubsection{Preparative experiments for photoproducts isolation}

The photoproducts were isolated by means of preparative TLCs of irradiation mixtures obtained by appropriate experiments. Their structures were determined by spectroscopic analyses (Hesse et al., 2008). The presence of functional groups was deduced by IR spectra and identification of all different protons and carbons was obtained by NMR spectra.

\subsubsection{Isolation of isoloratadine}

Loratadine (35 mg) was dissolved in $92 \mathrm{~mL}$ of $\mathrm{H}_{2} \mathrm{O} / \mathrm{CH}_{3} \mathrm{CN}\left(75: 25 \mathrm{v} / \mathrm{v}, 1 \times 10^{-3} \mathrm{M}\right)$ and divided in four closed quartz tubes. Each solution was saturated with argon and irradiated by UV-B lamps. After 20 min of irradiation the solvents were evaporated under vacuum and the residue was analysed by ${ }^{1} \mathrm{H}$ NMR and separated by preparative TLC. Elution with $\mathrm{Et}_{2} \mathrm{O}$ gave a fraction consisting of $\mathbf{3}$ and $\mathbf{4}$ (2 mg), isoloratadine $\mathbf{2}(6 \mathrm{mg})$, loratadine $\mathbf{1}$ (3 $\mathrm{mg})$ and an intractable polar material $(11 \mathrm{mg})$.

Ethyl 4-(8-chloro-6,11-dihydro-5H-benzo[5,6]cyclohepta[1,2-b]pyridin-11-yl)-5,6-

dihydropyridine-1(2H)-carboxylate (2): EI-MS m/z 382/384; $\mathrm{UV}_{\max }\left(\mathrm{CH}_{3} \mathrm{OH}\right) \mathrm{nm} 266(\log \varepsilon$ 3.8); $\mathrm{IR} v_{\max }\left(\mathrm{CHCl}_{3}\right) 1690$ (-N-CO-O- ), 1606 (stretching vibrations of aromatic rings), 1371 (C-O stretching) $\mathrm{cm}^{-1} ;{ }^{1} \mathrm{H}$ NMR $\left(500 \mathrm{MHz}, \mathrm{CDCl}_{3}\right) \delta 8.39(1 \mathrm{H}, \mathrm{d}, J=4.0 \mathrm{~Hz}, \mathrm{H}-2), 7.42(1 \mathrm{H}, \mathrm{d}, J=7.3$ Hz, H-4), 7.20-7.12 (4H, m, H-3, H-7, H-9 and H-10), 4.84-4.80 (2H, m, H-11 e H-3'), 4.10 (2H, q, $J=7.0 \mathrm{~Hz}, \mathrm{CH}_{2} \mathrm{O}$ ), 3.88 (2H, m, H-2'), 3.50-3.45 (4H, m, ), 2.88-2.74 (2H, m ), 1.94-1.71 (2H, m,), $1.23\left(3 \mathrm{H}, \mathrm{t}, J=7.0 \mathrm{~Hz}, \mathrm{CH}_{3}\right) .{ }^{13} \mathrm{C}$ NMR $\left(126 \mathrm{MHz}, \mathrm{CDCl}_{3}\right) \delta 157.0(\mathrm{C}-1 \mathrm{a}), 155.5(\mathrm{CO}), 146.8(\mathrm{C}-$ 2), 141.8 (C-6a), 138.5 (C-4), 135.9 (C-10a), 135.0 (C-4a), 133.1 (C-7), 133.0 (C-8), 131.1 (C-4'), 129.8 (C-10), 126.3 (C-9), 122.4 (C-3), 121.1 (C-3'), 62.3 (C-11), $61.2\left(\mathrm{CH}_{2} \mathrm{O}\right), 43.4$ (C-2'), 40.5 (C-6'), 31.3 (x2, C-5 e C-6), 28.0 (C-5'), $14.9\left(\mathrm{CH}_{3}\right)$.

\subsubsection{Isolation of compounds 3 and 4}


205 Loratadine $(50 \mathrm{mg})$ was dissolved in $130 \mathrm{~mL}$ of $\mathrm{H}_{2} \mathrm{O} / \mathrm{CH}_{3} \mathrm{CN}\left(75: 25\right.$, v/v, $\left.1 \times 10^{-3} \mathrm{M}\right)$ and irradiated 206 by UV-B lamps. The irradiation mixture was analyzed at different time by HPLC. After 40 min of 207 irradiation the solvents were evaporated under vacuum, and the residue was analysed by ${ }^{1} \mathrm{H}$ NMR 208 and separated by preparative TLC. Elution with $\mathrm{Et}_{2} \mathrm{O}$ gave a fraction consisting of $\mathbf{3}$ and $\mathbf{4}$ in ca. 3:1 209 molar ratio (11 mg), tricycle $\mathbf{3}(2 \mathrm{mg})$, isoloratadine $\mathbf{2}(2 \mathrm{mg})$, loratadine $\mathbf{1}(5 \mathrm{mg})$ and an intractable 210 polar residue $(8 \mathrm{mg})$.

211 8-Chloro-6,11-dihydro-5H-benzo[5,6]cyclohepta[1,2-b]pyridine (3): EI-MS m/z 229/231; UV $\lambda_{\max }$ $212\left(\mathrm{CH}_{3} \mathrm{OH}\right) \mathrm{nm}: 279$ (log $\varepsilon$ 3.1); IR $v_{\max }\left(\mathrm{CHCl}_{3}\right) 1580$ (stretching vibrations of aromatic ring), 1070 213 (aryl C-halogen stretching) $\mathrm{cm}^{-1} ;{ }^{1} \mathrm{H}$ NMR $\left(500 \mathrm{MHz}, \mathrm{CDCl}_{3}\right) \delta 8.35(1 \mathrm{H}, \mathrm{d}, J=4.9 \mathrm{~Hz}, \mathrm{H}-2), 7.40$ $214(1 \mathrm{H}, \mathrm{dd}, J=7.5,1.4 \mathrm{~Hz}, \mathrm{H}-4), 7.20$ (1H, d, $J=8.1 \mathrm{~Hz}, \mathrm{H}-10), 7.16$ (3H, m, H-4, H-7 and H-9), 2154.35 (2H, s, H-11), 3.33 (4H, brs, H-5 and H-6); ${ }^{13}$ C NMR (50 MHz, CDCl $) \delta 156.9(\mathrm{C}-1 \mathrm{a}), 146.5$ 216 (C-2), 140.8 (C-6a), 137.7 (C-4), 136.0 (C-10a), 133.8 (C-4a), 132.3 (C-8), 130.7 (C-10), 128.9 (C217 7), 126.3 (C-9), 122.0 (C-3), 35.7 (C-11), 31.3 (C-5 and C-6).

218 Spectral data of piperidinone $\mathbf{4}$ were deduced by those of the mixture of $\mathbf{3}$ and $\mathbf{4}$ after the signals of 219 tricycle 3 were subtracted; it was identified by comparison of its signals with those reported in 220 literature (Hirsch and Havinga, 1976).

221 Ethyl 4-oxopiperidine-1-carboxylate (4) (in mixture with 3 in ca. 1:3 molar ratio): EI-MS $\mathrm{m} / \mathrm{z}$ 171; $222{ }^{1} \mathrm{H}$ NMR $\left(500 \mathrm{MHz}, \mathrm{CDCl}_{3}\right) \delta 4.19\left(2 \mathrm{H}, \mathrm{q}, J=7.1 \mathrm{~Hz}, \mathrm{CH}_{2} \mathrm{O}\right), 3.76(4 \mathrm{H}, \mathrm{t}, J=6.1 \mathrm{~Hz}, \mathrm{H}-2$ and $\mathrm{H}-$ 223 6), $2.45\left(4 \mathrm{H}, \mathrm{t}, J=6.1 \mathrm{~Hz}, \mathrm{H}-3\right.$ e H-5), $1.29\left(3 \mathrm{H}, \mathrm{t}, J=7.1 \mathrm{~Hz}, \mathrm{CH}_{3}\right) .{ }^{13} \mathrm{C} \mathrm{NMR}\left(125 \mathrm{MHz}, \mathrm{CDCl}_{3}\right)$ $224 \delta 207.1(\mathrm{C}-4), 155.0(\mathrm{CO}), 61.8\left(\mathrm{CH}_{2} \mathrm{O}\right), 43.0(\mathrm{C}-2$ and $\mathrm{C}-6), 41.1,(\mathrm{C}-3$ and $\mathrm{C}-5), 14.6\left(\mathrm{CH}_{3}\right)$.

2.4.4.3.UV-B irradiation experiments for mechanistic purposes

Two $1 \times 10^{-3} \mathrm{M}$ solutions of loratadine in pure $\mathrm{CH}_{3} \mathrm{CN}$ were prepared by dissolving $5 \mathrm{mg}$ in $13 \mathrm{~mL}$. A solution was irradiated in open quartz tubes and the other one in closed quartz tubes after saturating with argon. After $15 \mathrm{~min}$ the solvent was evaporated and each residue analysed by ${ }^{1} \mathrm{H}$ 229 NMR.

230 A similar procedure was used for two $1 \times 10^{-3} \mathrm{M}$ solutions of loratadine in methanol and for two 231 solutions of loratadine in $\mathrm{H}_{2} \mathrm{O} / \mathrm{CH}_{3} \mathrm{CN}(7: 3 \mathrm{v} / \mathrm{v})$.

2.4.4.4 Irradiation of isolaratadine 2

233 A $1 \times 10^{-4}$ M solution of compound 2 in $\mathrm{H}_{2} \mathrm{O} / \mathrm{CH}_{3} \mathrm{CN}(9: 1 \mathrm{v} / \mathrm{v})$ was irradiated in open quartz tubes 234 with UV-B lamps and analysed by HPLC and ${ }^{1} \mathrm{H}-\mathrm{NMR}$.

\subsubsection{Irradiation of desloratadine 5} $1 \times 10^{-3} \mathrm{M}$ solution of desloratadine 5 was prepared by dissolving $5 \mathrm{mg}$ in $16 \mathrm{~mL}$ of $\mathrm{H}_{2} \mathrm{O} / \mathrm{CH}_{3} \mathrm{CN}$ 7:3 v/v. The solution was irradiated by UV-B lamps and analysed by ${ }^{1} \mathrm{H}-\mathrm{NMR}$. 
239 Samples were dissolved in dimethylsulphoxide (DMSO, 3\% v/v), stored in the dark at $4{ }^{\circ} \mathrm{C}$, further 240 diluted in deionized water (Elix 10, Millipore, Milan, Italy) and sonicated for 30 minutes to obtain 241 stock solutions. The test solutions were prepared by mixing the appropriate volumes of the stock solutions and ISO test media. Toxicity assays were performed in the following organisms: the green alga Pseudokirchneriella subcapitata, the planktonic rotifer Brachionus calyciflorus abundant in freshwaters, the anostracan crustacean Thamnocephalus platyurus, highly sensitive in acute toxicity testing and the cladoceran crustacean Ceriodaphnia dubia, worldwide distributed and often employed in acute and chronic toxicity testing.

\subsubsection{Determination of drugs concentration in test samples}

The concentrations of drugs were measured $(\mathbf{n}=\mathbf{1})$ using the solid phase extraction (SPE) coupled with HPLC. Each test solution containing drugs at the beginning of each toxicity test and after $24 \mathrm{~h}$, $48 \mathrm{~h}$ and $72 \mathrm{~h}$ passed through a C18 Sep-Pak® light column (Waters) used as a solid phase extraction cartridge, previously conditioned with $5.0 \mathrm{~mL}$ methanol followed by $5.0 \mathrm{~mL}$ water. The cartridge was then eluted with $5 \mathrm{~mL}$ methanol. The eluate was evaporated to dryness under reduced pressure and the residue was suspended in $1.0 \mathrm{~mL}$ acetonitrile. Portions of $200 \mu \mathrm{L}$ volume were then injected into the HPLC system.

\subsubsection{Acute toxicity tests}

B. calyciflorus organisms were hatched from cysts (MicroBioTest Inc., Nazareth, Belgium) in synthetic moderately hard freshwater $(80-100 \mathrm{mg} / \mathrm{L} \mathrm{CaCO} 3, \mathrm{pH} 7.5 \pm 0.3)$ at $25 \pm 1{ }^{\circ} \mathrm{C}$ under continuous illumination (3000-4000 lux) for 16-18 h prior to test initiation, as reported in the ASTM E 1440-91 guidelines. Six replicates with five animals/well, less than $2 \mathrm{~h}$ old, were performed for each concentrations $(0.3 \mathrm{~mL}$ of test solution for each test well in 36 -well plates, MicroBioTest Inc., Nazareth, Belgium) of each compound.

The T. platyurus test was performed in according to ISO 14380 (2011) using larvae hatched from

267 The $C$. dubia test was performed over $24 \mathrm{~h}$ of exposure using young organisms less than $24 \mathrm{~h}$ old cysts (Thamnotoxkit F, MicroBioTest Inc., Nazareth, Belgium) in 20-22 $\mathrm{h}$ before the assay in the standard freshwater (dilution 1:8 with deionized water) at $25^{\circ} \mathrm{C}$ under continuous illumination (3000-4000 lux). Tests were performed in 24-well plates with 10 crustaceans/well $(1.0 \mathrm{~mL}$ of test following test conditions reported in EPA-600-4-90 (US EPA 1993) with slight modifications. Neonates of at least third generation coming from a healthy mass culture (starting organisms were purchased from Aquatic Research Organisms, Inc., Hampton, NH, USA) were maintained at $25 \pm 1$ ${ }^{\circ} \mathrm{C}$ in synthetic medium (hardness $250 \mathrm{mg} / \mathrm{L}$ expressed as $\mathrm{CaCO}_{3}$ ) with a 16:8 h light:dark cycle 
(600 lux) Tests were performed in 24-well plates with 10 crustaceans per well $(1.0 \mathrm{~mL}$ of test 273 solution), in three replicates.

274 For each test considered above, both a negative control (only test-medium) and a solvent control 275 (DMSO 1\% v/v related to the maximum concentration of compounds tested equal to $100 \mathrm{mg} / \mathrm{L}$ ) 276 were performed. The plates were incubated in darkness at $25^{\circ} \mathrm{C}$ for $24 \mathrm{~h}$.

277 The end-point considered was mortality, and the concentration resulting in a $50 \%$ effect in $24 \mathrm{~h}$ 278 exposure was indicated as Median Lethal Concentration (LC50).

279 In acute assays, compounds were tested for a maximum of eight dilutions depending on the 280 respective sensitivity of the organisms (100-31.25-9.76-3.15-0.98-0.31-0.09 mg/L) starting from the 281 highest concentration of $100 \mathrm{mg} / \mathrm{L}$ with a geometric progression of 3.2.

\section{2.5.3 Chronic toxicity tests}

283 The B. calyciflorus chronic test was based on the offspring reduction over $48 \mathrm{~h}$ exposure (ISO, 284 20666, 2008) and was performed on young organisms less than $2 \mathrm{~h}$ old. Cysts were hatched as 285 previously described for the acute test. Tests were performed in 48-well plates with one rotifer/well 286 (0.9 mL of test solution prepared in moderately hard dilution water, ASTM E1440-91), in six 287 replicates. The organisms were fed with a fresh suspension $(0.1 \mathrm{~mL})$ of $10^{7}$ cells $/ \mathrm{mL}$ of the unicellular alga $P$. subcapitata. Plates were incubated in darkness at $25{ }^{\circ} \mathrm{C}$.

The chronic test in C. dubia was performed with female neonates $<24$ h old from at least the third generation of a stock culture maintained in synthetic water with ISO medium were individually exposed to $25 \mathrm{~mL}$ of test solution in beakers over 7 days (ISO, 20665, 2008). Tests were conducted in semi-static conditions (all test media were exchanged five times per week) and, from the fourth day-exposure onward, the offspring produced by each parent organism were counted and removed daily. The organisms were fed daily with $200 \mu \mathrm{L}$ of a combination of yeast Saccharomyces cerevisiae, alfalfa and flake food in addition to the unicellular green alga $P$. subcapitata $\left(10^{8}\right.$ cells $/ \mathrm{mL})$. Ten replicates per concentration were incubated at $25 \pm 1{ }^{\circ} \mathrm{C}$ with a $16: 8 \mathrm{~h}$ light:dark cycle (600 lux).

The $P$. subcapitata growth inhibition test was performed according to OECD 201, 2011 with slight modifications reported by Paixao et al., 2008. The single samples were incubated with $10^{4}$ cells $/ \mathrm{mL}$ of algal suspension in 96-well microplates in six replicates under continuous illumination at $25 \pm 1$ ${ }^{\circ} \mathrm{C}$ on a microplate shaker $(450 \mathrm{rpm})$. The plates were read at $450 \mathrm{~nm}$ (SpectraFluor, Tecan, Switzerland) immediately before the test and after $24 \mathrm{~h}, 48 \mathrm{~h}$ and $72 \mathrm{~h}$.

For all chronic tests, a negative control (test-medium control) was used to the test series. Only for $P$. subcapitata growth inhibition test, the \% DMSO exceeded the maximum \% recommended in toxicity testing $(0.01 \%)$. Thus, for this kind of assay, a solvent control (DMSO $0.1 \% \mathrm{v} / \mathrm{v}$ related to 
the maximum concentration of compounds tested equal to $10000 \mu \mathrm{g} / \mathrm{L}$ ) was performed. The number

307 of the offspring or the algal growth outputs were compared to the values obtained for the negative

308 control in order to determine the chronic effective percentages and to evaluate the chronic Effective

309 Concentrations (ECx).

310 In B. calyciflorus and C. dubia chronic assays, compounds were tested for a maximum of nine

311 dilutions (1000-312.5-97.66-30.52-9.54-2.98-0.93-0.29-0.09 $\mu \mathrm{g} / \mathrm{L})$ starting from the highest

312 concentrations of $1000 \mu \mathrm{g} / \mathrm{L}$ with a geometric progression of 3.2. For the P. subcapitata growth

313 inhibition test, compounds were tested for a maximum of ten dilutions (10000-3125-976.56-305.17-

$31495.37-29.80-9.31-2.91-0.91-0.28 \mu \mathrm{g} / \mathrm{L})$ starting from the highest concentration of $10000 \mu \mathrm{g} / \mathrm{L}$ with

315 a geometric progression of 3.2 .

316 2.5.4 Ecotoxicological data analysis

317 For each kind of assay, three independent experiments were performed. For each independent

318 experiment, the effect percentages were calculated comparing each specific negative control. For

319 each assay, the effect percentages coming from three independent experiments were pooled using

320 Prism5 software (Graphpad Inc., CA, USA) to estimate the concentrations giving $\mathrm{x} \%$ effect

$321(\mathrm{~L}(\mathrm{E}) \mathrm{Cx})$ by non-linear regression (log agonist vs. normalized response-variable slope). The LC50

322 value, corresponding to the $50 \%$ of mortality for each test-organism, was the test parameter for

323 acute tests, whereas EC50, EC20, and EC10 were the concentrations giving $50 \%, 20 \%$ or $10 \%$ of

324 the effect used in chronic tests to evaluate the inhibition of reproduction or the inhibition of the

325 algal growth.

\section{Results}

The SPE coupled with HPLC analysis revealed a non-appreciable difference between nominal and actual concentrations: the actual concentrations of tested chemicals diverged from the nominal concentrations by $5 \%$ after $24 \mathrm{~h}$, around $10 \%$ after $48 \mathrm{~h}$, and around $15 \%$ after $72 \mathrm{~h}$. According to Li (2012), when the actual concentrations are at least $80 \%$ of the nominal concentrations, the measured and the expected concentrations are considered to be very close and no significantly different, so that in the present study the effective concentrations are reported as nominal concentrations.

3.1 Photochemical behaviour of loratadine

Loratadine $\mathbf{1}$ is slightly soluble in water, hence acetonitrile was chosen as co-solvent to obtain clear solutions (Figure 1). Preliminary experiments were carried out in the dark using $1 \times 10^{-4} \mathrm{M}$ solutions in $\mathrm{H}_{2} \mathrm{O} / \mathrm{CH}_{3} \mathrm{CN}$ 9:1 v/v. The drug was stable after $48 \mathrm{~h}$ even when tested in acidic ( $\left.\mathrm{pH} 4\right)$ 
340 and alkaline ( $\mathrm{pH}$ 9) solutions. These $\mathrm{pH}$ ranges are usually considered in environmental analysis 341 (Valenti et al., 2009).

342 Loratadine solution was then irradiated in a photoreactor with UV-B lamps. HPLC analysis 343 showed the formation of photoproducts already after 2 min (Figure 2): compound 2 at $\mathrm{R}_{\mathrm{t}} 16.2 \mathrm{~min}$ 344 and compound 3 at $\mathrm{R}_{\mathrm{t}} 10.2 \mathrm{~min}$ (Figure 1). The photoproducts were identified comparing their $\mathrm{R}_{\mathrm{t}}$ 345 values with those of standard compounds which were isolated and characterized by performing 346 preparative photochemical experiments.

347 Kinetic experiment under these conditions showed that loratadine has a half-life of 137.4 348 seconds and a polychromatic quantum yield of $5.89 \times 10^{-4}$ (Table S1).

349 Preparative experiments to isolate and characterize the photoproducts were carried out by UV-B 350 irradiation of $1 \times 10^{-3} \mathrm{M}$ solutions of the drug in $\mathrm{H}_{2} \mathrm{O} / \mathrm{CH}_{3} \mathrm{CN}$ 75:25 v/v. HPLC analysis confirmed 351 the trend observed in dilute conditions and revealed the presence of the peaks of products $\mathbf{2}$ and $\mathbf{3}$ 352 together with other minor products. After $40 \mathrm{~min}$ of irradiation, TLC on silica gel afforded three 353 photoproducts: compounds 2 and 3 and a new product 4. Structures 2-4 (Figure 1) were assigned on 354 the basis of spectral data. In particular, 1D and 2D NMR spectroscopy was used because it is a 355 powerful technique for identification and structure elucidation of small organic molecules 356 (Elyashberg, 2015; Fuloria and Fuloria, 2013).

357 The mass spectrum of photoproduct $2\left(\mathrm{R}_{\mathrm{t}} 16.5 \mathrm{~min}\right)$ shows a molecular peak at $382 / 384 \mathrm{~m} / \mathrm{z}$ 358 corresponding to the molecular formula $\mathrm{C}_{22} \mathrm{H}_{23} \mathrm{ClN}_{2} \mathrm{O}_{2}$, hence suggesting that it is a loratadine 359 isomer. The mass spectrum evidences a peak at $m / z 154$, absent in the mass spectrum of loratadine, 360 attributable to the tetrapyridine fragment $\mathrm{C}_{8} \mathrm{H}_{12} \mathrm{NO}_{2}$. The ${ }^{1} \mathrm{H}-\mathrm{NMR}$ spectrum shows significant 361 differences only in the aliphatic proton region. In particular, two overlapping signals due to protons $362 \mathrm{H}-11$ and H-3' (singlet + multiplet, respectively) are observed at $\delta 4.80$ as expected due to the shift 363 of the double bond. The shift of the double bond produces, in the ${ }^{13} \mathrm{C}-\mathrm{NMR}$ spectrum, the 364 disappearance of the singlet carbon signal at $\delta 133.3$ (C-11 of 1) and the appearance of a doublet 365 carbon signal at $\delta 120.8\left(\mathrm{C}^{3} 3^{\prime}\right.$ of 2$)$.

366 The structure of photoproduct $3\left(R_{t} 10.2 \mathrm{~min}\right)$ was confirmed by the presence in the mass spectrum 367 of molecular peak at $229 / 231 \mathrm{~m} / \mathrm{z}$ corresponding to the molecular formula $\mathrm{C}_{14} \mathrm{H}_{12} \mathrm{ClN}_{2}$. The ${ }^{1} \mathrm{H}-$ 368 NMR spectrum shows the presence of six aromatic protons in the $\delta$ range 8.40-7.10, of signals at $\delta$ 3694.35 and at $\delta 3.33$ due to di-benzylic methylene proton $\mathrm{H}-11$ and to benzylic methylene protons $\mathrm{H}-5$ 370 and H-6, respectively.

371 Piperidinone 4 was obtained by TLC in mixture with compound $\mathbf{3}$ (ca. 1:3 molar ratio) and its data 372 were deduced by comparison with those reported in literature (Hirsch and Havinga, 1976). It was 373 not observed by HPLC analysis since it is transparent at the selected wavelength $(254 \mathrm{~nm})$ of the 
detector. Its presence in the irradiation mixture was confirmed by GC-MS (Figure 2) and ${ }^{1} \mathrm{H}-\mathrm{NMR}$ analysis of the crude irradiation mixture.

NMR analysis was particularly useful to examine the irradiation mixtures since loratadine and its photoproducts 2-4 have characteristic identifiable signals.

Aqueous solutions of the drug were also exposed to sunlight in Naples (Italy) in July 2017, under environmental-like conditions. As expected, degradation was slower. HPLC analysis showed a decrease of drug concentration to approximately $50 \%$ after 2 days and a complex mixture of photoproducts. The chromatographic and spectroscopic analysis of the irradiation mixture showed the presence of photoproducts $\mathbf{2 - 4}$.

\subsection{Mechanistic interpretation}

In order to gain more mechanistic information on photoproducts formation, UV-B irradiation experiments were performed under various conditions (in different solvents such as acetonitrile, methanol, water/acetonitrile; in the presence and absence of oxygen) and the reactions were monitored by HPLC and ${ }^{1} \mathrm{H}$ NMR. The experimental conditions and the results are reported in Table S2.

Accordingly with previous data (Abounassif et al., 2005), loratadine degraded faster in solutions containing water (after 15 min of irradiation only $5 \%$ photodegradation in methanol or acetonitrile vs. $55 \%$ in $\mathrm{H}_{2} \mathrm{O} / \mathrm{CH}_{3} \mathrm{CN} 7: 3 \mathrm{v} / \mathrm{v}$, Table $\mathrm{S} 2$ runs $\left.\mathbf{c}, \mathbf{e}, \mathbf{g}\right)$. In all irradiation conditions, especially under argon, photoproduct $\mathbf{2}$ was present while the formation of compounds $\mathbf{3}$ and $\mathbf{4}$ was observed only in aqueous solution. Control experiments showed that isoloratadine $\mathbf{2}$ was photolabile and converted to unidentified material after 20 min of UV-B irradiation.

On the basis of literature data, a plausible mechanistic interpretation is reported in Figure 3. Compound 2 should derive from a 1,3-hydrogen shift, probably via a radical pair, from an excited triplet state of loratadine $\mathbf{1}$, as suggested by the quenching with oxygen. The radical recombination can give loratadine $\mathbf{1}$ or its isomer $\mathbf{2}$ (Turro et al., 2010a). Addition of water to give intermediate $\mathbf{6}$ and $\beta$-cleavage of the alkoxy radical intermediate 7 should give products 3 and 4. $\beta$-Cleavage of alkoxy radicals to give ketones and stable radicals is well known (Turro et al., 2010b).

In all the experimental irradiation conditions, desloratadine $\mathbf{5}$ was not observed. This result is not surprising considering that the carbamate function is quite photostable and it does not absorb light in the UV-C and UV-B regions (Iesce et al., 2006). However, control experiments showed that when a $1 \times 10^{-3} \mathrm{M}$ solution of desloratadine 5 in $\mathrm{H}_{2} \mathrm{O} / \mathrm{CH}_{3} \mathrm{CN}$ 7:3 v/v was irradiated by UV-B lamps as reported above for loratadine, it was photodegraded within 60 min and gave a complex mixture of products among which the sole identifiable product was tricycle 3 . 
409 Tests were performed with loratadine 1, and its photoisomer $\mathbf{2}$ and the mixture of compounds $\mathbf{3}$ and

4104 (in ca. 3: 1 molar ratio) obtained by preparative experiments (see 2.4.4). We also examined

411 desloratadine 5 and its photodegradation mixture (DPM) obtained as reported in 2.4.4.5.

4123.4 Acute toxicity results

413 In order to verify that the acute effects were not DMSO-dependent, a solvent control was performed

414 for each kind of assay, at the highest tested percentage $(1 \% \mathrm{v} / \mathrm{v})$, and referred to the highest tested 415 concentration of $100 \mathrm{mg} / \mathrm{L}$, observing no significant difference with the negative control, with a 416 survival higher than the $90 \%$ both in negative and in solvent controls (Table S3) as recommended 417 by test validity criteria. The parent compound loratadine, its metabolite desloratadine, the 418 transformation products and the degradation mixture of desloratadine were found to cause mortality 419 in both crustaceans and rotifers and the LC50 values, obtained after $24 \mathrm{~h}$ exposure (coming from 420 three independent experiments pooled using Prism5) are reported in Table 1. In addition, LC50 421 values espressed as mean \pm SD of the indipendent experiments are reported in Table S4. Loratadine 422 was able to cause the $50 \%$ of mortality in $C$. dubia at hundreds of $\mu \mathrm{g} / \mathrm{L}$, differently from the effects 423 found at dozens of $\mathrm{mg} / \mathrm{L}$ in the rotifers and in the anostracan crustacean. On the other hand, all the 424 aquatic organisms showed the same sensitivity to the metabolite, with LC50 values found at units of $\mathrm{mg} / \mathrm{L}$, while DPM was more active in the rotifer B. calyciflorus (LC50 equal to $2.02 \mathrm{mg} / \mathrm{L}$ ) than in crustaceans. Transformation products such as isoloratadine $\mathbf{2}$ and the mixture of tricycle $\mathbf{3}$ and piperidinone 4 showed different acute effects. In fact, albeit isoloratadine was more effective in $C$. dubia $(\mathrm{LC} 50=1.19 \mathrm{mg} / \mathrm{L})$, the mixture of tricycle 3 and piperidinone 4 caused $50 \%$ mortality at units of $\mathrm{mg} / \mathrm{L}$ not only in the cladoceran crustacean but also in the rotifer and it is more lethal than parent loratadine 1 for B. calyciforus (Table 1). To the best of our knowledge, scientific data on the aquatic toxicity of the compounds here tested is rather scarce. Nevertheless, there are several data on diphenhydramine (DPH), the same histamine H1-receptor antagonist as loratadine. In 2013

433 Goolsby and collaborators found that the diphenhydramine (DPH) was acutely toxic in C. dubia 434 with an LC50 value equal to $3.94 \mathrm{mg} / \mathrm{L}$, while in 2015 Kristofco at al., found that DPH caused a $43550 \%$ immobilisation in the cladoceran crustacean Daphnia magna at $374 \mu \mathrm{g} / \mathrm{L}$ after $48 \mathrm{~h}$-exposure 436 and the $50 \%$ mortality in the fish Danio rerio at $45.5 \mathrm{mg} / \mathrm{L}$ after $72 \mathrm{~h}$ exposure. In the 2011 , 437 Berninger et al. found a median acute effect in D. magna at $0.37 \mathrm{mg} / \mathrm{L}$ after DPH exposure and 438 from units to dozens of $\mathrm{mg} / \mathrm{L}$ in the fish Pimephales promelas. Differently from vertebrates which are known to possess some degree of genetic homology for DPH targets like histamine-H1 receptors, with a similarity from 40 to $70 \%$ (Gunnarsson et al., 2008, Berninger et al., 2011), the effects of the antihistamines in invertebrates may likely be related to other mechanisms of actions 
442 affecting histamine ion channel transporters, as suggested by Haas et al., 2008 and Berninger et al.,

443 2011. Regarding transformation products, they were found to be slightly toxic for all aquatic

444 organisms tested excepted isoloratadine 2 in $C$. dubia. Although acute toxicity data are generally

445 very far from those of environmental concern and from the water solubility of chemicals, they

446 are still relevant regarding the assessment of environmental risk since chronic data are often

447 lacking.

$448 \quad 3.5$ Chronic toxicity results

449 The chronic toxicity data for the five samples, reported as EC50, EC20, and EC10 values (coming 450 from three independent experiments pooled using Prism5) and expressed in $\mu \mathrm{g} / \mathrm{L}$, are shown in

451 Table 2. In addition, EC50 values espressed as mean \pm SD of the indipendent experiments are 452 reported in Table S5. In order to verify that the chronic effects were not DMSO-dependent, a 453 solvent control was performed only for $P$. subcapitata growth inhibition assay, at the highest tested 454 percentage $(0.1 \% \mathrm{v} / \mathrm{v})$, and referred to the highest tested concentration of $10000 \mu \mathrm{g} / \mathrm{L}$, as explained 455 above. No significant difference with the negative control was found, with a growth higher than the $45690 \%$ both in negative and in solvent controls (Table S3) as recommended by test validity criteria. 457 Loratadine 1 was the most chronically active compound in the rotifer (EC50=51.32 mg/L), while 458 its metabolite desloratadine 5 was the most active both in $C$. dubia, with a median effective 459 concentration at few units of $\mu \mathrm{g} / \mathrm{L}$, and in the green alga $P$. subcapitata $(\mathrm{EC} 50=220.20 \mu \mathrm{g} / \mathrm{L}$ ), as 460 also depicted in Figure 4, where the concentration/effect curves of samples are reported for each 461 aquatic organism. As shown in Figure 4, the parent compound was less active in C. dubia than its 462 metabolite but more active than the transformation products. Furthermore, DPM determined a 463 median chronic toxic effect at hundreds or thousands $\mu \mathrm{g} / \mathrm{L}$, in the case of aquatic consumers and 464 producers, respectively (Table 2). In fact, as also reported in Figure 4, differently from consumers 465 (C. dubia and B. calyciflorus), in producers ( $P$. subcapitata) there is a slow increase in 466 concentration/effect relationship with an evident response only at the highest concentrations. 467 In 2015 Watanabe and collaborators tested the diphenhydramine histamine H1-receptor antagonist 468 in the alga $P$. subcapitata finding an EC50 value equal to $1240 \mu \mathrm{g} / \mathrm{L}$, the same order of magnitude 469 of the EC50 obtained in this study.

470 In the 2009, Isidori and collaborators tested the ranitidine, a histamine H2-receptor antagonist in the 471 consumers $C$. dubia and B. calyciflorus finding a median offspring reduction in the order of 472 thousands of $\mu \mathrm{g} / \mathrm{L}$, therefore underlining a higher sensitivity of these aquatic organisms to 473 histamine H1- than to histamine H2-receptor antagonists. The environmental chronic toxicity of the 474 histamine H1-receptor antagonist such as loratadine and its derivatives towards the aquatic tested 475 organisms is observable already at few units-dozens $\mu \mathrm{g} / \mathrm{L}$ (EC20 values, Table 2), however these 
residues occur in surface waters at ng/L levels which are too low to cause an immediate threat to exposed organisms but can pose delayed long term effects interfering with organism metabolic pathways.

The EC10 and EC20 values of loratadine and EC10, EC20 and EC50 values of desloratadine (Table 2) are lower than their respective water solubility equal to $11 \mu \mathrm{g} / \mathrm{L}$ and $3950 \mu \mathrm{g} / \mathrm{L}$, making the results of this study interesting to understand the behaviour of these drugs in real water samples. At the best of our knowledge, no data of photoproducts water solubility is available.

\section{Conclusion}

Loratadine $\mathbf{1}$ is transformed either under UVB or by sunlight exposure. The reactive site is the double bond while the carbamate moiety is unreactive. Transformation products derive by photoisomerization and water photoaddition followed by a cleavage reaction. Photolability is also observed in desloratadine 5 but this drug leads to a complex photodegradation mixture.

The toxic effects of loratadine $\mathbf{1}$ and desloratadine $\mathbf{5}$ occur in both acute and chronic assays at concentrations higher than their environmental occurring concentrations differently affecting the organisms selected from two trophic levels. However, the environmental transformations of the parent compounds, here simulated by the UV-irradiation treatments, lead to the formation of a bioactive mixture of residues and transformation products, which could represent a harmful combination to some of the organisms tested. In order to define water quality criteria protective for all aquatic species, further toxicity studies towards other aquatic species are needed especially to increase species sensitivity diagrams used in EU and North American approach to anti-histamine management to derive water quality benchmark, and to broaden knowledges of mechanisms involved in the different biological responses of the organisms.

\section{Acknowledgement}

This research did not receive any specific grant from funding agencies in the public, commercial, or not-for-profit sectors.

\section{References}

Abounassif, M.A., El-Obeid,H.A., Gadkariem,E.A., 2005. Stability studies on some benzocycloheptane antihistaminic agents. J. Pharm. Biomed. Anal. 36, 1011-1018. ASTM E 1440-91, 2004. Standard Guide for Acute Toxicity with the Rotifer Brachionus. American Society for Testing and Materials, Philadelphia PA, USA reapproved. 
Berninger,J.P., Brooks,B.W, 2010. Leveraging mammalian pharmaceutical toxicology and pharmacology data to predict chronic fish responses to pharmaceuticals. Toxicol. Lett. 193, 6978.

Berninger,J.P., Du,B., Connors, A.K.,Eytcheson,S.A., Kolkmeier,M.A., Prosser,K.N., Valenti Jr, T.V., Chambliss, K.C., Brooksyz, B.W., 2011. Effects of the antihistamine diphenhydramine on selectedaquatic organisms. Environ. Toxicol. Chem. 30, 2065-2072.

DellaGreca, M., Isidori, M., Temussi,F., 2014. Toxicity and Risk of Transformation Products of Emerging Contaminants for Aquatic Organisms: Pharmaceutical Case Studies, in: Lambropoulou, D. A., Nollet, L. M. (Eds.), Transformation Products of Emerging Contaminants in the Environment: Analysis, Processes, Occurrence, Effects and Risks, Wiley, Chichester (UK), pp. 827-858.

Dulin, D., Mill, T., 1982. Development and evaluation of sunlight actinometers. Environ. Sci. Technol. 16, 815-820.

El-Awady M., Bela, F., Pyell, U. 2013. Robust analysis of the hydrophobic basic analytes loratadine and desloratadine in pharmaceutical preparations and biological fluids by sweeping - cyclodextrin-modified micellar electrokinetic chromatography. J. Chromatogr. A 1309, 64-75.

Elyashberg, M. 2015. Identification and structure elucidation by NMR spectroscopy. Trends Analyt. Chem. 69, 88-97.

Fuloria, N. K., Fuloria, S. 2013. Structural Elucidation of Small Organic Molecules by 1D, 2D and Multi Dimensional-Solution NMR Spectroscopy. J. Anal. Bioanal.Tech. S11: 001. DOI: 10.4172/2155-9872.S11-001.

Goolsby, E.W., Mason, C.M., Wojcik, J.T., Jordan,A.M., Black,M.C., 2013. Acute and chronic effects of diphenhydramine and sertraline mixtures in Ceriodaphnia dubia. Environ. Toxicol. Chem. 32, 2866-2869.

Gunnarsson, L., Jauhiainen, A., Kristiansson, E., Nerman, O., Joakim Larsson, D.G., 2008. Evolutionary conservation of human drug targets in organisms used for Environmental risk assessments. Environ. Sci. Technol. 42, 5807-5813.

Haas, H.L., Sergeeva, O.A., Selbach, O., 2008. Histamine in the Nervous System. Physiol. Rev. 88, 1183-1241.

Hesse, M., Meier, H., Zeeh, B. 2008. Spectroscopic Methods in Organic Chemistry. Thieme, Stuttgart (DE).

Hirsch,J.A., Havinga, E., 1976.The 1-hetera-4-cyclohexanone system. Proton and carbon-13 magnetic resonance, transannular effects, and conformational analysis. J. Org. Chem. 41, 455462.

Iesce,M.R., DellaGreca,M.Cermola, F., Rubino, M.,Isidori, M.,Pascarella, L., 2006. Transformation and ecotoxicity of carbamic pesticides in water. Environ. Sci. Pollut. Res. Int. 13, 105-109.

Isidori, M., Lavorgna, M., Russo, C., Kundi, M., Žegura, B., Novak, M., Filipiè, M., Mišï, M., Knasmueller, S., de Alda, M.L., Barcelï, D., Žonja, B., Èesen, M., Šèanèar, J., Kosjek, T., Heath, E., 2016. Chemical and toxicological characterisation of anticancer drugs in hospital and municipal wastewaters from Slovenia and Spain. Environ. Pollut. 219, 275-287.

Isidori, M., Parrella, A., Pistillo, P.,Temussi, F., 2009. Effects of ranitidine and its photoderivatives in the aquatic environment. Environ. Int. 35, 821-825.

ISO 14380, 2011. Water Quality-Determination of the Acute Toxicity to Thamnocephalus Platyurus (Crustacea, Anostraca). International Organization for Standardization, Geneva, Switzerland.

ISO 20665, 2008. Water Quality-determination of Chronic Toxicity to Ceriodaphnia Dubia in 7 Days-population Growth Inhibition Test. International Organization for Standardization, Geneva, Switzerland.

ISO 20666, 2008. Water Quality-determination of Chronic Toxicity to BrachionusCalyciflorus in 48 H-population Growth Inhibition Test. International Organization for Standardization, Geneva, Switzerland. 
Kosonen, J., Kronberg, L., 2009. The occurrence of antihistamines in sewage waters and in recipient rivers. Environ. Sci. Pollut. Res. Int. 16, 555-564.

Kristofco, L.A., Brooks,B.W., 2017. Global scanning of antihistamines in the environment: analysis of occurrence and hazards in aquatic systems. Sci. Total Environ. 592, 477-487.

Kristofco, L.A., Du, B., Chambliss, C.K., Berninger, J.P., Brooks, B.W., 2015. Comparative Pharmacology and Toxicology of Pharmaceuticals in the Environment: Diphenhydramine Protection of Diazinon Toxicity in Danio rerio but not Daphnia magna. The AAPS Journal 17, 175-183.

Lambropoulou, D. A., Nollet, L. M. 2014. Transformation Products of Emerging Contaminants in the Environment: Analysis, Processes, Occurrence, Effects and Risks, Vol. 1 and 2, Wiley, Chichester (UK),

Li, M.-H., 2012. Survival, mobility, and membrane-bound enzyme activities of freshwater planarian, dugesia japonica, exposed to synthetic and natural surfactants. Environ. Toxicol. Chem. 31 (4), 843-850.

López-Serna, R., Petrovic, M., Barceló, D., 2012. Direct analysis of pharmaceuticals, their metabolites and transformation products in environmental waters using on-line TurboFlow ${ }^{\mathrm{TM}}$ chromatography-liquid chromatography-tandem mass spectrometry. J. Chromatogr. A. 1252, 115-129.

Moreno-González, R., Rodriguez-Mozaz, S., Gros, M., Barceló, D., León, D.M. 2015. Seasonal distribution of pharmaceuticals in marine water and sediment from a mediterranean coastal lagoon (SE Spain). Environ. Res. 138, 326-344.

OECD 201, 2011. Guideline for the Testing of Chemicals 201: Freshwater Alga and Cyanobacteria, Growth Inhibition Test. Organization for Economic Cooperation and Development.

Paixao, S.M., Silva, L., Fernandes, A., O'Rourke, K., Mendonca, E., Picado, A., 2008. Performance of a miniaturized algal bioassay in phytotoxicity screening. Ecotoxicology 17, 165-171.

Parfitt, K., 1999. Martindale: The extra Pharmcopoeia (32 nd ed).Pharmaceutical Press: London, 413449.

Passananti, M., Lavorgna, M., Iesce, M. R., DellaGreca, M., Brigante, M., Criscuolo, E., Cermola, F., Isidori, M., 2015. Photochemical fate and eco-genotoxicity assessment of the drug etodolac. Sci. Total Environ. 518-519, 258-265.

Peyrovi, M., Hadjmohammadi, M., 2015. Extraction optimization of Loratadine by supramulecular solvent-based microextraction and its determination using HPLC. J. Chromatogr. B 980, 41-47.

Radjenovic', J, Petrovic, M., Barcelo', D. 2009. Fate and distribution of pharmaceuticals in wastewater and sewage sludge of the conventional activated sludge (CAS) and advanced membrane bioreactor (MBR) treatment. Water Res. 43, 831-841.

Ramanathan, R., Reyderman, L., Kulmatycki,K., Su, A.D., Alvarez, N., Chowdhury, S.K., Alton,K.B., Wirth, M.A., Clement, R.P., Statkevich, P., Patrick, J.E., 2007. Disposition of loratadine in healthy volunteers. Xenobiotica 37, 753-769.

Turro, N.J., Ramamurthy, V., Scaiano, J.C., 2010a. Modern Molecular Photochemistry of Organic Molecules. University Science Books, Sausalito (USA), pp. 705-728.

Turro, N.J., Ramamurthy, V., Scaiano, J.C. 2010b. Modern Molecular Photochemistry of Organic Molecules. University Science Books, Sausalito (USA), pp. 665-668.

US EPA, 1993. Methods for Measuring the Acute Toxicity of Effluents and Receiving Waters to Freshwater and Marine Organisms. EPA-600-4-90, fourth ed. US Environmental Protection Agency, Washington DC.

Valcarcel, Y., Gonzalez Alonso, S., Rodriguez-Gil, J. L., Gil, A., Català, M. 2011. Detection of pharmaceutically active compounds in the rivers and tap water of the Madrid Region (Spain) and potential ecotoxicological risk. Chemosphere, 84, 1336-1348.

Valenti,T.W.J., Perez-Hurtado, P., Chambliss, C.K., Brooks, B.W., 2009. Aquatic toxicity of sertraline to Pimephales promelas at environmentally relevant surface water $\mathrm{pH}$. Environ. Toxicol. Chem. 28, 2685-2694. 
613 Watanabe, H., Tamura, I., Abe, R., Takanobu, H., Nakamura, A., Suzuki, T., Hirose, A., Nishimura, T., Tatarazako, N., 2016. Chronic Toxicity Of An Environmentally Relevant Mixture Of Pharmaceuticals To Three Aquatic Organisms (Alga, Daphnid, And Fish). Environ. Toxicol. Chem. 35, 996-1006.

Witiak, D.T., 1970. Antiallergenic agents, in Burger, A. (Ed.) Medicinal chemistry (3rd ed). Wiley Interscience, New York, Chapter 65.

Yumibe, N., Huie, K., Chen,K.J., Snow, M., Clement,R.P., Cayen,M.N., 1996. Identification of human liver cytochrome $\mathrm{P} 450$ enzymes that metabolize the nonsedating antihistamine loratadine. Formation of descarboethoxyloratadine by CYP3A4 and CYP2D6. Biochem. Pharmacol. 51, 165-172. 